\title{
Entre o individual e o coletivo: uma análise acerca da trajetória de Vera Silvia Magalhães e José Roberto Spiegner na esquerda armada brasileira (1966-1970)
}

\author{
Between the individual and the collective: an analysis of the trajectory of \\ Vera Silvia Magalhães and José Roberto Spiegner in the \\ Brazilian armed left (1966-1970)
}

Higor Codarin

\begin{abstract}
Resumo Este artigo tem por objetivo analisar a trajetória de Vera Sílvia Magalhães e José Roberto Spiegner na luta armada contra a ditadura civil-militar brasileira. Tendo como objetivo compreender a opção e manutenção da luta armada, buscamos transcender o prisma das organizações políticas, que reivindicavam a legitimidade do caminho armado a partir de perspectivas conjunturais socioeconômicas e políticas. Para tanto, optamos pela investigação da trajetória de dois indivíduos que partilharam desta escolha. Por intermédio desta trajetória, que amalgamou amor e revolução, levantaremos outros aspectos presentes em uma organização de esquerda armada brasileira, como a ruptura com os costumes, a vida na clandestinidade e o compromisso com o projeto revolucionário e com os companheiros.
\end{abstract}

Palavras-chave Esquerda armada. Brasil. Guerrilha. Ditadura.

\begin{abstract}
This article aims to analyze the trajectory of Vera Sílvia Magalhães and José Roberto Spiegner in the armed struggle against the Brazilian civil-military dictatorship. In order to understand the option and maintenance of the armed struggle, we sought to go beyond the political organizations' prism, which claimed its legitimacy from perspectives of socioeconomic and political conjunctures. To do that, we analyze the trajectory of two individuals who shared this choice. Through this trajectory, which has amalgamated love and revolution, we will raise other aspects present in an organization of the Brazilian armed left, such as the rupture with customs, life in the underground and commitment to the revolutionary project and with the companions.
\end{abstract}

Keywords Armed left. Brazil. Guerrilla. Dictatorship.

a Doutorando em História pela Universidade Federal Fluminense e Mestre em Sociologia pela Universidade Estadual de Campinas. 
Era difícil

jurar amor eterno

estando com a cabeça

à prêmio

pois a vida podia terminar

antes do amor

(Alex Polari, Inventário de Cicatrizes, 1978).

\section{INTRODUÇÃO}

Este artigo tem como principal objetivo analisar a trajetória de dois militantes da esquerda armada contra a ditadura civil-militar brasileira ${ }^{1}$, Vera Ślvia Magalhães e José Roberto Spiegner. Como prelúdio a isso, demonstraremos brevemente de que modo as análises biográficas podem contribuir ao conhecimento histórico.

A relativamente recente "reabilitação" do gênero biográfico como possibilidade fecunda de produção de conhecimento histórico, após o "eclipse da narrativa" (RICOEUR, 1994), acompanhou - ou foi acompanhada de - um reposicionamento significativo do papel do indivíduo na historiografia (LoRIGA, 1998, p. 225). A partir dos anos 70 e 80 houve um (re) encontro, nas palavras de Mary Del Priore (2009), entre o indivíduo e a História, tornando-o relevante como sujeito.

Apesar de essencialmente concebida a partir da construção narrativa de trajetórias de vida, para a análise biográfica se tornar relevante ao conhecimento histórico, deve distanciar-se de uma proposta analítica que enclausure os indivíduos hermeticamente em si mesmos, desconsiderando e descaracterizando as relações sociais em que estavam inseridos e que, no limite, conferiram sentido às suas escolhas. Conforme aponta Norbert Elias, em $A$ sociedade dos indivíduos, devemos ter sempre em vista a "inerradicável interdependência" entre os agentes, os elos invisíveis, mutáveis, constituintes de uma cadeia de relações sociais que atravessam os indivíduos (ELIAs, 1994, p. 20).

Nessa perspectiva, a análise da trajetória de vida deve, em uma de suas facetas, propor-se enquanto a "monografia de toda uma época" (GRAMSCI apud MARTINHO, 2012, p. 316), ou, nas palavras de Walter Benjamin: “[...] demonstrar como a exis-

1 Optamos pela utilização do termo "civil-militar" ao nos referenciarmos à ditadura brasileira. A consolidação do termo "ditadura militar" tende, nos embates pela construção da memória coletiva, a isentar parcelas importantes da sociedade civil que participaram, inclusive com auxílio financeiro, na gênese do golpe e manutenção da ditadura. No entanto, devemos citar que não propomos uma atribuição genérica à responsabilidade da sociedade. Utilizamos o termo civil-militar para demonstrar, principalmente, o caráter de classe do golpe e da ditadura, apoiando-nos, assim, na perspectiva proposta por Ridenti (2016). 
tência inteira de um indivíduo cabe numa de suas obras, num de seus fatos [e] como, nessa existência insere-se uma época inteira" (BENJAMIN apud Dosse, 2015, p. 11).

Contudo, se realçamos, de um lado, a importância do meio social na relação entre indivíduo e sociedade, afirmando a força das relações sociais na construção do sujeito, as análises a respeito das trajetórias individuais adquirem, por outro lado, um papel fundamental para discutir e representar questões relacionadas à dicotomia "escolhas individuais e determinações sociais", fazendo erigir, assim, a figura do indivíduo enquanto sujeito histórico. Conforme aponta o historiador italiano Giovanni Levi, se a liberdade do indivíduo não é absoluta, sendo culturalmente e socialmente determinada, como propusemos acima, “[...] ela continua sendo, no entanto, uma liberdade consciente. [...] Na verdade, nenhum sistema normativo é suficientemente estruturado para eliminar qualquer possibilidade de escolha consciente" (Levi, 2006, p. 179).

A análise da trajetória individual, portanto, combinando essa dupla condição dos sujeitos, torna-se relevante enquanto produtora de conhecimento histórico por ressignificar as relações entre indivíduo e sociedade. Nesse sentido:

[...] o indivíduo é, ao mesmo tempo, ator crítico e produto de sua época, seu percurso iluminando a história por dois ângulos distintos. Um explícito, pela iniciativa voluntária do observador que propõe uma análise da sociedade na qual o personagem está inscrito. O outro, implícito, avaliado no percurso do personagem que ilustra, por sua vez, as tensões, conflitos e contradições de um tempo, todos essenciais para a compreensão do período (Del PRIORE, 2009, p. 11).

Tendo isso em vista, a investigação sobre a trajetória de Vera Sílvia Magalhães e José Roberto Spiegner levanta questões importantes a respeito dos aspectos coletivos e individuais presentes no imaginário dos agrupamentos que propuseram a luta armada contra a ditadura brasileira.

\section{DO MOVIMENTO SECUNDARISTA À PRAIA VERMELHA}

Vera Sílvia e José Roberto se conheceram ainda no pré-golpe civil-militar de 1964. No entanto, iniciaram o envolvimento afetivo e político após o 31 de março, tendo como pano de fundo o movimento secundarista do Estado da Guanabara ${ }^{2}$. Ambos militavam politicamente em seus respectivos colégios, ela pelo grêmio

2 Após a transferência da capital da federação para Brasília, a antiga capital foi transformada em um estado autônomo: o estado da Guanabara. O estado do Rio de Janeiro tinha como capital a cidade de Niterói. 
estudantil do colégio Andrews, onde escrevia artigos de esquerda para o jornal Ser Comunista e onde comandou uma greve contra as mensalidades, e ele pelo Pedro II - que junto ao Colégio da Aplicação (CAp) eram os dois principais redutos da esquerda no movimento secundarista da Guanabara -, onde editava uma revista de esquerda chamada Diálogos Estudantis. A queda de João Goulart, desprovida de resistência significativa, foi um choque para ambos.

Já naquele momento, e ainda que de forma desarticulada, Vera e José Roberto teciam críticas à passividade do Partido Comunista Brasileiro (PCB), principal força hegemônica de esquerda do contexto, pela falta de mobilização e resistência diante de - para usarmos a expressão de Caio Prado Júnior (1987) - "uma passeata militar". Apesar da perplexidade com a qual encaravam a conjuntura resultante, fortaleceram sua atuação política no movimento secundarista durante o biênio 1965-1966, que, por sua vez, exerceu papel auxiliar na retomada e reestruturação do movimento estudantil da Guanabara pela esquerda universitária, iniciado através dos centros acadêmicos da Faculdade Nacional de Filosofia (FNFi) e da Faculdade Nacional de Direito (FND), ambas vinculadas à antiga Universidade do Brasil (UB), recém rebatizada de Universidade Federal do Rio de Janeiro (UFRJ).

Em 1966, quando realizaram curso preparatório para o vestibular, engrossaram as fileiras das manifestações promovidas pelo movimento estudantil universitário, principalmente relacionadas à cobrança das anuidades - proposta pelo governo Castello Branco por influência das recomendações da United States Agency for International Development (USAID), através dos acordos entre esta e o Ministério da Educação e Cultura (MEC) - e à situação dos universitários excedentes, isto é, os estudantes aprovados no vestibular mas que não obtinham vagas para ingressar nas universidades (MARTins FilHo, 1987). Assim, como participantes do que ficou caracterizado como movimento dos vestibulandos, puderam observar as organizações políticas que mobilizavam as passeatas estudantis, entrevendo a possibilidade de construir uma alternativa, de esquerda, à proposta política do PCB. Neste período, Vera ingressou em uma das várias dissidências estudantis que se organizavam clandestinamente no interior do PCB, a Dissidência Universitária da Guanabara (DI-GB). Já José Roberto não tinha uma perspectiva clara naquele momento, e optaria pela DI-GB apenas no ano seguinte, quando, assim como Vera, ingressou na faculdade de Economia da Universidade Federal do Rio de Janeiro, localizada no campus da Praia Vermelha.

\section{O CAMINHO DA LUTA ARMADA: COLETIVO E INDIVIDUAL}


Conforme apontado acima, a DI-GB foi uma das diversas dissidências estaduais estudantis do PCB que se estruturaram no período pós-golpe de $1964^{3}$. Constituída enquanto fração clandestina ao partido antes do golpe, junto aos centros acadêmicos da FNFi e da FND, cultivava críticas à postura política do partido, que se intensificaram após a queda de João Goulart, quando elegeram o PCB como principal responsável pela conjuntura resultante, principalmente devido aos "desvios de direita" que impregnavam sua linha política. Desvios estes que o teriam impulsionado para uma prática política reboquista - com relação a João Goulart e, consequentemente, à burguesia -, etapista e, sobretudo, pacifista. Compelidos por novos modelos revolucionários, derivados da revolução chinesa e, principalmente, da revolução cubana, e questionadores da hegemonia soviética enquanto propagadora de definições tático-estratégicas do movimento comunista internacional, suas críticas refletiam uma necessidade candente de oposição à inação do partido. O tempo era de ação. Irrompia no horizonte a perspectiva de refundar a esquerda nacional, com objetivo de torná-la, efetivamente, revolucionária.

A DI-GB constituiu-se como organização autônoma em novembro de 1966, sendo a primeira das dissidências a romper com o partido, após imbróglio envolvendo as recomendações pecebistas para a campanha eleitoral. Serviu como estímulo ao processo de ruptura o aumento significativo da presença da organização em outros centros acadêmicos da UFRJ, como também a reativação, na clandestinidade, da União Metropolitana dos Estudantes (UME), cuja presidência ficou a cargo da Dissidência e auxiliou na rearticulação do movimento estudantil das demais universidades, possibilitando, consequentemente, novos contatos para a organização. Grande parte desse avanço dizia respeito ao início de uma nova tática política promovida pelos dissidentes para a atuação no movimento estudantil. Ao contrário da utilização do movimento como aparato auxiliar dos agrupamentos políticos na luta contra a ditadura, proposta encampada pela Ação Popular (AP), principal organização em disputa pela hegemonia do movimento estudantil da Guanabara com a DI-GB, os dissidentes construíram a perspectiva de que as pautas do movimento estudantil deveriam representar problemáticas dos estudantes.

3 Além da DI-GB, organizaram-se no interior do PCB: Dissidência do Rio de Janeiro (DI-RJ), que se tornaria o primeiro Movimento Revolucionário 8 de Outubro; Dissidência do Rio Grande do Sul (DI-RS), que formaria o Partido Operário Comunista (POC) com remanescentes da POLOP; Dissidência de São Paulo (DI-SP), que se integraria à Ação Libertadora Nacional (ALN) ou à Vanguarda Popular Revolucionária (VPR) e Vanguarda Armada Revolucionária-Palmares (VAR-Palmares); Dissidência da Bahia (DI-BA), que promoveria uma fusão com a DI-GB; e, Dissidência de Minas Gerais (DI-MG) que integraria a CORRENTE (Ridenti, 2010). 
Através dessa tática, a Dissidência cresceu significativamente no biênio 19671968, quando atuou como principal vanguarda política do movimento estudantil. Este, naquele momento, tornou-se o principal setor social de oposição à ditadura por realizar diversas passeatas e protestos, seja contra os acordos MEC-USAID, a presença imperialista no Brasil ou reivindicativas de problemáticas específicas das universidades (МоттA, 2014). A forte repressão com que foram respondidas as manifestações sensibilizou diversos setores sociais, principalmente após a morte do estudante secundarista Edson Luís, em março de 1968, em protesto pela manutenção e melhoria na qualidade do restaurante estudantil Calabouço. Foi nesse contexto de crescente sensibilização social que os estudantes conseguiram promover uma passeata com cem mil pessoas, a "Passeata dos Cem Mil”, em junho de 1968.

Em paralelo com a tática junto ao movimento estudantil, a Dissidência avaliava maneiras de responder, na prática, a postura política que tanto criticava no PCB. Para isso, encontrou respaldo em novas leituras teóricas, tanto conjunturais quanto tático-estratégicas, que desafinavam das propostas pecebistas. Com relação às leituras conjunturais, ganharam relevância as análises contemporâneas a respeito da inserção do Brasil em um sistema mundial de exploração, por intermédio das relações tecidas pelo capitalismo em sua fase monopolista, que promoviam, consequentemente, uma crítica à visão dualista da sociedade brasileira. Nesta perspectiva inseria-se a leitura de Caio Prado Júnior, em A revolução brasileira (1966), como também, e principalmente, as leituras de Rui Mauro Marini, Theotônio dos Santos e André Gunder Frank. Este último, inclusive, em sua obra A agricultura brasileira: capitalismo e mito do feudalismo (1964), procurou relacionar o atraso no campo brasileiro não a "resquícios feudais", como apontava a análise do PCB, mas sim a uma característica inerente ao sistema capitalista, que promoveria, a um só tempo, “desenvolvimento e subdesenvolvimento”.

Além dessas, as teses de Celso Furtado (1964) sobre a estagnação econômica duradoura exerciam forte influência. Apropriadas de maneira seletiva, serviam à conclusão de que a construção e manutenção da ditadura eram tentativas de solucionar o impasse do capitalismo brasileiro. Em conjunto, construíram a visão da "utopia do impasse", conforme expressão de Daniel Aarão Reis (1990). Além das perspectivas teóricas que diziam respeito, especificamente, à conjuntura nacional, acrescentaram-se as leituras conjunturais internacionais, como Capitalismo Monopolista (1966), de Paul Baran e Paul Sweezy, que, à mesma maneira de Gunder Frank, afirmava a existência de uma cadeia global de exploração e postulava o protagonismo dos países periféricos como vanguarda no processo de 
internacionalização do socialismo. Assim, a grande maioria do universo teórico dos dissidentes apontava não apenas para uma crítica severa à leitura dualista do PCB, como também colocava na ordem do dia a possibilidade de realização da revolução brasileira.

Nesta perspectiva, para dar consequência às leituras conjunturais, desenvolviam debates sobre formas tático-estratégicas de realizar a revolução, promovendo uma síntese entre as visões de Lênin sobre a organização e atuação partidária, de um lado, e os novos modelos revolucionários provindos, principalmente, da revolução cubana, de outro. De Lênin, exercia forte influência as obras Que Fazer? e $O$ Estado e a Revolução. Do primeiro, Que fazer?, apropriaram não apenas a importância do papel da teoria para desenvolvimento do processo revolucionário, mas também a importância de jornais para educação política, as prerrogativas para as ações de agitação e propaganda e, também, a perspectiva de profissionalização dos quadros (LÊNIn, 1986). Do segundo, O Estado e a Revolução, tomaram a concepção do Estado enquanto aparato burocrático-militar da classe dominante, com objetivo principal de manutenção da dominação de classe. Além disso, apossaram-se da perspectiva de tomada do Estado pela via violenta, à qual acoplaram a concepção da guerra de guerrilhas, proporcionada pelas sistematizações relacionadas ao processo revolucionário cubano. Estas, propostas principalmente por Che Guevara (1987) e Debray (s.d), contemplavam a visão do foco guerrilheiro como fator principal para o desenvolvimento do projeto revolucionário, a qual concebia, consequentemente, a figura do guerrilheiro como ponto fundamental da revolução. Na frase clássica de Debray: "o motorzinho [foco guerrilheiro] que coloca em marcha o grande motor [a ação das massas]" (Debray, s.d, p. 58).

Em meio a esses debates, a segunda metade do ano de 1968 concedeu o impulso final para a adesão da DI-GB à luta armada. O que entre a cisão com o PCB e as passeatas estudantis de 1968 eram dúvidas, a conjuntura do segundo semestre transformou em certezas. Com o declínio do movimento estudantil, impulsionado, entre outros fatores, pela postura repressiva da ditadura - que culminou, ao final do ano, no Ato Institucional número 5 (AI-5) - e pelas primeiras ações armadas de outras organizações, a DI-GB percebeu que o caminho não apenas possível, mas inexorável, era a adesão às armas. O "golpe dentro do golpe", na visão dos dissidentes, era a prova cabal do impasse irresolvível do capitalismo no Brasil, que também impossibilitava qualquer forma de manutenção das forças de mobilização estudantis anteriores. Assim, a partir do final de 1968, a DI-GB deu início à preparação do primeiro grupo responsável pela realização das ações armadas. Realizando as primeiras ações armadas no início de 1969, todas tendo em vista 
angariar fundos, a organização promoveu sua III Conferência, em abril, que concretizou, oficialmente, a via da luta armada como estratégia revolucionária. A partir daquele momento deixaram para trás o estigma estudantil, transformando-se em Dissidência Comunista da Guanabara.

Contudo, a opção pela luta armada congregava outros aspectos, não identificáveis por intermédio da chave interpretativa mobilizada acima, isto é, através de um perfil analítico que tome apenas a Dissidência como organização coletiva, que mobiliza propostas e práticas políticas através de leituras conjunturais e debates teóricos. Para um quadro completo é necessário avaliar a opção a partir da perspectiva individual, e neste sentido, a trajetória de Vera Sílvia e José Roberto, principal objetivo deste artigo, é simbólica por agregar diversos desses aspectos.

Vera, como já dissemos, passou a militar pela DI-GB antes de ingressar na faculdade de Economia. José Roberto entraria no ano seguinte, em 1967, quando, em conjunto com os demais militantes da DI-GB radicados na faculdade, conquistaram o diretório acadêmico. Os dois se tornaram, rapidamente, quadros importantes da organização. Ambos, entre 1968 e 1969, eram assistentes teóricos nos grupos de estudo que a Dissidência desenvolvia, clandestinamente, sobre realidade brasileira e marxismo através dos centros acadêmicos que controlava. Esses funcionavam como um dos principais meios de recrutar novos militantes.

Além das obras que apontamos acima, Vera e José Roberto desenvolviam discussões que transcendiam as leituras conjunturais ou tático-estratégicas, trazendo para os debates outras perspectivas, indicativas da necessidade de romper com as referências normativas da sociedade. Nesse campo, destaca-se, principalmente, a obra de Wilhelm Reich, A revolução sexual, na qual, partindo de uma perspectiva relacional entre psicologia e sociologia, o autor promove uma crítica ácida à moral sexual vigente na sociedade, relacionando-a ao capitalismo. Objetivando o matrimônio como pedra angular dessa moral sexual, que reprime os indivíduos e constrói um muro "entre eles e a vida" (RеIch, 1981, p. 20), Reich percebe na revolução social o caminho para a destruição dessa moral e fruição dos indivíduos reprimidos sexualmente. Conforme suas próprias palavras: “Toda moral nega a própria vida, e a revolução social parece não ter tarefa mais importante do que possibilitar finalmente ao homem, ao ser humano vivo, a satisfação e a realização de sua vida" (REICH, 1981, p. 31).

Se o ponto central dos debates sobre o status quo dos costumes recaía sobre a questão dos relacionamentos afetivos, impulsionado, também, pela conjuntura de 1968, esses debates estavam relacionados a uma questão maior, que dizia respeito a quais práticas sociais poderiam ou não ser consideradas revolucionárias. Nesse 
sentido, os dissidentes propunham uma discussão que envolvia a necessidade de construir, na própria prática militante, o "homem-novo". Recolocado na década de 1960 por Che Guevara ${ }^{4}$ como necessidade imperativa no decorrer do processo de construção do comunismo, o conceito foi apropriado dos textos de juventude de Marx, especificamente dos Manuscritos Econômico-Filosóficos, de 1844, que chegava ao Brasil por intermédio da obra de Erich Fromm, O conceito marxista de homem, de 1961.

Portanto, podemos notar que para os dissidentes o contexto social de 1968 e o universo teórico congregavam duas perspectivas revolucionárias, uma social e outra individual. Neste sentido, a opção pela luta armada despontava, também, como um processo de revolução individual, existencial, enquanto esboços de "homens-novos", que, na própria prática revolucionária romperiam não apenas com a estrutura econômica que oprimia e explorava a grande maioria da população brasileira, mas também possibilitaria a emancipação humana.

Nesta perspectiva, não poderiam restringir esse debate à esfera das discussões teóricas. Como rudimentos do "homem-novo" que surgiria deveriam torná-las práticas. Assim, para Vera e José Roberto, naquele momento já namorados, a relação afetiva tinha de ser desenvolvida de maneira poligâmica, conforme aponta Vera5: "Era uma proposta nossa. A gente se amava profundamente, mas amava outras pessoas. Tínhamos 18, 19 anos. A monogamia não existe, é uma proposta burguesa, conservadora” (MAGALHÃEs, 1986). Além disso, para Vera, especialmente, a militância e os relacionamentos adquiriam, em conjunto, um sentido de questionamento e quebra do papel social atribuído a ela como mulher, conforme podemos notar neste depoimento que concedeu:

Eu tinha, na minha cabeça, que precisava fazer uma revolução pessoal. Uma proposta de relação afetiva diferente, achava um bode aquela perspectiva de casamento dos meus pais, queria ser melhor. Era uma coisa importante, ter

4 Fica clara a concepção de Che Guevara a respeito do "homem-novo" em discurso de março de 1965, denominado El socialismo y el hombre en Cuba, integrando-a como parte indispensável do processo revolucionário: "Para construir o comunismo, de forma simultânea à transformação das bases materiais, há que se fazer o homem-novo. [...] Neste período de construção do socialismo, podemos ver o homem-novo nascendo. Sua imagem não está, contudo, acabada; não poderia estar nunca, já que o processo avança em paralelo com o desenvolvimento das novas formas econômicas" (GuEvarA, 1968, p. 631-632).

5 Os depoimentos pessoais dos militantes da esquerda armada, realizados posteriormente, são de suma importância, não apenas para o objetivo deste artigo, como para todas as análises que busquem deslindar a experiência da luta armada pela perspectiva individual. Contudo, deve-se ressaltar as problemáticas e os cuidados que envolvem a utilização dessas fontes, que desnudam as relações conflitivas entre história e memória. Para perspectivas teóricas que tratam dessa questão e que nortearam este artigo, cf. Becker (2006), Pollack (1989) e Sarlo (2007). 
uma relação igual com um homem. Essa foi uma batalha importante, para mim, naquela época. A militância foi uma forma de ruptura com tudo isso. Era uma forma de sair de tudo isso e parecia que levaria a um caminho revolucionário. A revolução era de costumes também, não era só uma revolução social. Em determinados momentos, em termos de opção individual, enquanto agentes, enquanto sujeitos dessa história, o grande motor foi uma ruptura dos costumes (MAGALHÃEs, 1986).

Todavia, essa tentativa de ruptura com os padrões normativos era conflituosa e seletiva, além de não se fazer presente na totalidade dos quadros da organização. Se, por um lado, a ruptura com a monogamia e o matrimônio eram perspectivas relativamente consolidadas, outras práticas eram reprimidas, como foi o caso do uso de drogas leves, como a maconha. Vera, neste momento dirigente da organização, era totalmente contra o uso, e, em depoimento, apresentou um panorama das discussões sobre o tema com José Roberto, representativo dessa ruptura seletiva com os padrões morais: "Nós tínhamos paus homéricos. Ele [José Roberto] me dizia: Você é muito pra frente para ter sua vida afetiva-sexual, para falar sobre isso teoricamente, mas sobre a maconha você fica em pânico" (MaGALHÃEs, 1986). O uso de maconha na organização gerou, inclusive, um comunicado oficial da direção postulando a proibição da utilização dentre os quadros (CHAIN, 1988).

\section{O SEQUESTRO DO EMBAIXADOR NORTE-AMERICANO E A CLANDESTINIDADE RIGOROSA}

Como dissemos, com a nova linha política, em abril de 1969, a DI-GB formalizou a opção pela luta armada. A partir dali, a organização dividiu-se em três frentes distintas de trabalho: Frente de Trabalho Armado (FTA), Frente de Trabalho nas Camadas Médias (FTCM) e Frente de Trabalho Operário (FTO). Essa nova divisão atendia a duas necessidades. Por um lado, possibilitava o desenvolvimento de táticas distintas para setores sociais distintos, ao mesmo tempo em que viabilizava a compartimentação de informações, dificultando, caso houvesse alguma prisão, o mapeamento total da organização por parte dos órgãos repressivos. Daí a máxima: "[...] cada um deve saber exclusivamente o suficiente para sua prática" (BNM 076, p. 316).

Vera, após a conferência de abril, foi deslocada da direção da organização para a FTA, acontecimento que, em sua análise posterior, foi também impulsionado pelo fato de ser mulher, realçando, assim, outro aspecto da ruptura seletiva com os costumes, tratada anteriormente: 
Eu sentia na pele essa questão dos costumes. Eu acho, independentemente de qualquer coisa, que eu sairia da direção em 1969 por diversas outras razões. Inclusive pelos quadros novos que estavam surgindo. Mas havia um argumento fantástico, alegando que eu era uma pessoa instável emocionalmente. Só que as pessoas que me diziam isso, eram os homens com quem eu namorava, e que estavam na direção. E eu me perguntava: por que eles não saem da direção? Por que eu sou instável emocionalmente? (MAGALHãEs, 1986).

Apesar desses questionamentos, aceitou a nova função, muito estimulada pela valorização da FTA no momento em que a organização aderia à luta armada. José Roberto seria integrado à FTCM, mantendo sua atuação na universidade e nos grupos de estudo, com o objetivo de angariar novos militantes e/ou simpatizantes.

Dali em diante, muito pelo desconhecimento da repressão com relação à DI-GB, a atuação de Vera e José Roberto corria sem grandes percalços. Em uma espécie de semiclandestinidade, Vera realizou diversas ações armadas com o objetivo de construir, como se dizia na época, a infraestrutura da organização, pela obtenção de armas e dinheiro. Nesse contexto, realizou uma ação de expropriação de dinheiro e joias na casa do então deputado federal pelo Movimento Democrático Brasileiro (MDB), Edgar Magalhães de Almeida, em agosto de 1969. Passando-se por repórter da revista Realidade, Vera agendou uma entrevista com o deputado para conhecer sua extensa coleção de obras de arte, que mantinha em sua casa, em Copacabana. Chegado o dia, com os demais participantes da ação, que se passavam por fotógrafo e assistente, logo após um rápido olhar por parte da coleção, Vera solicitou que todos os integrantes da família se reunissem na sala para realização de uma foto, com objetivo de facilitar a ação. Com todos reunidos no mesmo cômodo, anunciaram o assalto. Após relutância do deputado, abriram o cofre da residência, que resultou em trinta mil dólares e diversas joias. Antes de deixarem o apartamento, fizeram questão de se desvincularem dos criminosos comuns. Para acalmar o filho do deputado, Vera Sílvia lhe teria dito que aquela era uma encenação de um assalto, um assalto "[...] desses que você vê na televisão e que tem sido feito aos bancos" (BNm 603, p. 25).

Já rebatizados como Movimento Revolucionário 8 de Outubro (MR-8), após as diversas ações que realizaram, o Oito, como ficou popularmente conhecido, realizaria a ação mais ousada da esquerda armada brasileira: o sequestro do embaixador norte-americano, em setembro do mesmo ano. Com o objetivo inicial de libertar o principal líder de massas da organização, Vladimir Palmeira, preso no XXX Congresso da UNE em Ibiúna, realizado no ano anterior, o Oito aliou 
esta necessidade à perspectiva de realizar uma ação de propaganda que globalizaria, em escala nacional, os feitos da esquerda armada. Definiram a semana da pátria como momento ideal para realização do sequestro, tendo como objetivo romper a censura imposta aos meios de comunicação e combater a propaganda ufanista da ditadura. Pela grandiosidade da ação e pela necessidade de fortalecer a aproximação com as demais organizações armadas que se estruturavam naquele momento, buscaram realizá-la em conjunto, encontrando em Joaquim Câmara Ferreira, da ALN, a parceria desejada.

Vera foi responsável por realizar o levantamento das informações sobre a viabilidade da captura. Atuando como uma mulher jovem recém-chegada do interior, conseguiu as informações sobre o itinerário e a rotina do embaixador com seu chefe da segurança. Com isso, fixaram a data da realização do sequestro para o dia 4 de setembro. Na véspera, Vera decidiu encontrar-se com José Roberto. O encontro, rememorado por Vera, remonta à amálgama conflituosa entre amor e revolução na trajetória dos dois, fator que justifica a longa citação:

Passeamos, namoramos, conversamos. Eu não podia contar nada sobre o que iria ocorrer no dia seguinte. Só disse que ia me envolver numa barra-pesada e sumir por uns 20 dias. Pedi que ele ouvisse o rádio e que tomasse precauções. Ele insistiu que marcássemos um ponto inorgânico [sem conhecimento da organização] dali a dois dias. Eu disse que era contra as normas de segurança e não concordei. Fiquei de procurá-lo logo que pudesse. [...]

Com a fina ironia que cultivava, Zé Roberto se despediu de mim com o refrão de uma música de Gal: "É preciso estar atento e forte/ Não temos tempo de temer a morte”. Cantarolou, também, uma música de Noel Rosa: "Aí que mulher indigesta/ Merece um tijolo na testa". Depois disse: "Essa estanquização [compartimentação de informações] não tem nada a ver com o amor. Se a gente se ama a gente segura a barra juntos". [...]

Ele me chamava de Nenê. E disse: "Vai, Nenê, pra tua ação clandestina. Vocês nunca vão saber o que é o amor. Essa estanquização é ridícula. Me põe aí no teu bando" (Magalhães apud CARvalHo, 1998, p. 177).

Embora taticamente bem-sucedida, por viabilizar a libertação de quinze presos políticos e divulgar o manifesto nos principais meios de comunicação, o sequestro do embaixador estimulou a fúria repressiva do Estado, que, como consequência direta, atualizou a lei de Segurança Nacional, instituindo a pena de morte para crimes políticos, promulgou o AI-13, criando a prerrogativa de banimento político, 
e fortaleceu o aparato repressivo às organizações de esquerda armada (FICO, 2001). Ao contrário do desconhecimento que o caracterizava anteriormente, a ação do sequestro colocou o MR-8 como um dos principais alvos da repressão. Apesar de não sofrer perdas significativas imediatamente após a ação, com exceção da prisão de Cláudio Torres, a vida dos militantes do Oito mudaria radicalmente a partir daquele momento. Com Cláudio Torres foi encontrada uma conta de energia onde constava o endereço do apartamento que funcionava como centro de operações da FTA. Ali, os órgãos de repressão encontraram diversas informações sobre os militantes que participaram do sequestro, que foram imediatamente divulgadas. Vera, a partir de então, passou a ser uma das principais militantes da esquerda armada procurada pelos órgãos de repressão.

O MR-8, de modo geral, teve de se retrair. Todos os militantes enveredaram, completamente, para a clandestinidade. Deslocaram-se para regiões suburbanas da Guanabara onde além de dificultarem as ações da repressão, buscaram se aproximar dos setores sociais para dar seguimento à luta. Nesse período, José Roberto abandonou a faculdade e passou a viver em Niterói, esperando novas orientações da organização. Vera ficou "entocada”, conforme jargão da época, em diversos "aparelhos", de onde não podia sair para impedir qualquer possibilidade de prisão. Em depoimento relembra a apreensão que vivia neste período: "Na clandestinidade, tínhamos uma prática de vida completamente diferente. Eu ficava dentro de casa o dia inteiro, lendo, armada, e com muito medo. Achava que podia cair, ser presa, morrer a qualquer momento" (Magalhães, 1986). Além disso, ressalta as modificações que a vida clandestina acarretou na esfera afetiva, relacionando-as à sua relação com José Roberto: “[...] houve um retrocesso, do ponto de vista dos costumes. Com o isolamento que sofremos, eu tive de tornar minha relação monogâmica por força das circunstâncias" (MaGALHÃEs, 1986).

Nesse contexto, os laços afetivos com José Roberto, apesar de já significativos, intensificaram-se. Como estavam separados, a saudade de José Roberto fez com que Vera rompesse todas as regras de segurança. As comunicações por meio dos bilhetes, trazidos e enviados por outros membros da organização, não bastavam. Após insistência, conseguiu marcar um encontro. Não sabia onde estava José Roberto, mas Lúcia Murat, outra militante do Oito, sabia. Como era muito procurada, foi ao encontro de Lúcia na Praça XV irreconhecível, com peruca e maquiagem. Chegando em Niterói seguiu de olhos vendados para o apartamento em que estava José Roberto. O reencontro foi carregado de muita emoção, segundo relata Vera:

6 Jargão que designava os locais de moradia dos militantes na clandestinidade. 
"Foi um feliz reencontro. Nos beijamos muito, chorávamos e ríamos. Zé prometeu nunca mais me chamar de mulher indigesta. E eu prometi transgredir as normas orgânicas. [...] Zé tinha razão. [...] O amor transcende a tudo mesmo" (MAGALHÃEs, s.d, p. 29).

Apesar da felicidade no reencontro, discutiram com apreensão a situação precária em que estavam. O cerco repressivo se fechando, a possibilidade cada vez mais próxima da prisão, tortura e, no limite, da morte. Destinos cada vez mais frequentes para os militantes da esquerda armada. A última grande baixa havia sido Carlos Marighella, principal dirigente da ALN e vanguarda na ruptura com o PCB, assassinado em novembro de 1969. Nessa conjuntura, percebiam o forte impasse a que estavam submetidos. O sequestro do embaixador, apesar do sucesso tático, não impulsionou a luta armada como esperavam. Além disso, a clandestinidade dificultava o estabelecimento de conexão com os setores sociais que buscavam mobilizar. A marginalização social das organizações e dos militantes era evidente. José Roberto, diante da marginalização social progressiva, verbalizava suas dúvidas quanto ao sucesso da empreitada armada. Como podemos notar neste diálogo rememorado por Fernando Gabeira, também militante do MR-8, José Roberto assemelhava o isolamento social dos militantes à situação dos cosmonautas no espaço:

Ele segurou seu cachimbo suavemente, virou-se para mim e disse:

- Vinha andando para esse encontro e um cara no ônibus me dizia que os sequestradores do embaixador americano eram as pessoas que ele mais admirava. Os sequestradores do embaixador e os cosmonautas.

Depois disso, Zé Roberto me olhou bem nos olhos e perguntou: - Não somos cosmonautas, somos? (GABEIRA, 1979, p. 54).

Embora muito fragilizado, o Oito desenvolveu um processo de discussão entre os militantes para definir os rumos táticos da organização e buscar saídas possíveis aos novos problemas. Nesse processo, José Roberto foi um dos mais críticos em relação à manutenção da organização na luta armada. Atribuímos a ele um dos documentos deste processo de discussão, escrito sob o codinome "Saraiva", em que apesar de não vislumbrar qualquer tipo de alternativa tática concreta, há um prognóstico extremamente negativo para o futuro da organização caso continuassem com a prática armada: "Estamos isolados, nível de estrutura baixo, com poucas possibilidades de desenvolver esta estrutura, e cercados. [...] Até agora 
batemos com a cabeça na parede endurecendo-a, se continuarmos, quebraremos o pescoço" (BNM 076, p. 3430).

No entanto, apesar da visão crítica, a opção pela luta armada trazia consigo uma espécie de imperativo da ofensiva, que, se não impedia, dificultava muito qualquer alternativa que propusesse um recuo ou abandono da prática armada, mesmo que sua manutenção, como o prognóstico negativo de José Roberto apontava, pudesse levar à destruição da organização e à morte de seus militantes. Conforme sublinha Ridenti (2010), o imperativo ofensivo, mesmo que levasse militantes à morte, indicava uma contingência necessária do processo revolucionário. Nesse sentido, foram muito influenciados pelo foquismo cubano, que construiu as características necessárias aos guerrilheiros para o sucesso da revolução. A máxima de Debray ecoava na esquerda armada: "Vencer é aceitar, desde o princípio que a vida não é o bem supremo do revolucionário" (DEbraY, s.d, p. 37). Tendo em vista esse imaginário ofensivo, é possível compreender o aceite, por parte de José Roberto, para integrar a Direção da organização, após a ida de Franklin Martins para Cuba, e apesar das críticas que cultivava sobre a postura política do Oito. Em conjunto com Daniel Aarão Reis e Cid Benjamin, formou a trinca de dirigentes do MR-8 a partir do final de 1969, sendo responsável pela Frente de Trabalho nas Camadas Médias.

\section{A VIDA TERMINOU ANTES DO AMOR}

Apesar das dificuldades, Vera e José Roberto mantinham-se firmes no MR-8 e na luta armada, e, a partir daquele momento, não mais se separariam. Com a abertura de uma nova frente de trabalho em Salvador, resultado da unificação com parte da Dissidência do PCB da Bahia (DI-BA), o Oito precisava enviar alguém para comandar os trabalhos na capital baiana. Vera foi a escolhida para se tornar dirigente regional, fato que acarretaria, consequentemente, a separação de José Roberto, que teria de se manter na Guanabara. Não aceitaram. Insurgiram-se contra o centralismo da organização. Com isso, Lúcia Murat foi em seu lugar.

Após a recusa de Vera Sílvia em ir para a Bahia, os dois passaram a viver juntos. No contexto de deslocamento urbano que os militantes realizavam na clandestinidade, abriam-se novas perspectivas com relação aos contatos com os moradores das regiões para as quais se deslocavam. Conforme propõe Henri Acselrad, é possível notar um significativo “[...] encontro da militância clandestina com o cotidiano da população destas áreas da cidade, seja em relações de vizinhança, de coabitação ou através da simples circulação por suas ruas" (2015, p. 40). A partir desse encontro, ainda conforme Acselrad, é possível problematizar duas visões correntes sobre 
essa relação. Por um lado, a colaboração da população com a ditadura e, por outro, a referência ao total isolamento social, que seria inerente à condição de clandestinidade dos militantes, impedindo, portanto, o desenvolvimento, mesmo que fugaz, de relações com os moradores. Crítico dessas concepções, Acselrad mobiliza o conceito de "zona cinzenta" 7 para propor uma nova problemática:

[...] será que na chamada "zona cinzenta" situada entre o combate à ditadura e o apoio explícito a ela, não teria se configurado uma "zona urbana cinzenta"? Ou seja, que ainda sob a operação dos dispositivos repressivos destinados a imobilizar pelo medo "a sociedade governada", ter-se-ia verificado, em certas circunstâncias, em relação aos militantes, fora dos circuitos de resistência, manifestações de complacência, empatia ou cumplicidade? (ACSELRAD, 2015, p. 42).

Problemática que o próprio responde: “[...] em uma observação mais aguda, podemos admitir que, apesar do enorme retraimento da esfera pública, os clandestinos, de posse de suas novas identidades, teciam alguns laços com moradores das cidades" (ACSELRAD, 2015, p. 44).

A vivência de Vera e José Roberto, juntos, na clandestinidade, é simbólica disso. No final de 1969, eles passaram a morar em São Cristóvão, com César Benjamin, outro militante do MR-8, que tinha quinze anos. O casal, para evitar suspeitas, passava-se por primos mais velhos do "Menininho", codinome de César. Todavia, nesse período, os momentos de calmaria eram raros e fugazes. Algum tempo depois, tiveram de abandonar o apartamento por recomendação de César, que os avisou que o "aparelho" não era mais seguro. Com isso, passaram a residir com Carlos Zílio em outro "aparelho" do MR-8, localizado na rua Montevideo, 391, na Penha. Para evitar suspeitas, Vera, que passava boa parte do tempo no apartamento, incorporou o papel de dona-de-casa. No prédio, desenvolveu amizade com a vizinha de porta, Mirian Chaves, e passou a auxiliá-la no cuidado de seus filhos. José Roberto e Carlos Zílio passavam o dia fora, para manter a fachada de uma rotina normal de trabalho. Contudo, apesar das tentativas de manter as aparências, foram descobertos no dia 16 de fevereiro de 1970, ocasião que culminou no assassinato de José Roberto.

7 Zona cinzenta é um conceito do historiador Pierre Laborie que, apoiado na obra de Primo Levi, busca compreender a França e os franceses durante a ocupação nazista. Nesse sentido, procura analisar a sociedade francesa não por intermédio do maniqueísmo resistência/colaboração, mas direcionando a visão analítica para o espaço entre os dois polos e, mais ainda, para as atitudes ambivalentes, em que se pode ser um e outro ao mesmo tempo. Para maiores detalhes, cf. Laborie (2010). 
O apartamento, além de moradia, servia para realização de algumas reuniões entre José Roberto, Cid e Daniel. A última delas estava acontecendo na noite do dia 16 de fevereiro. Neste dia, a vizinha Mirian denunciou a presença de subversivos ao Departamento de Ordem Política e Social (DOPS) (BNm 076, p. 161). Contudo, contraditoriamente, momentos antes dos carros policiais chegarem, Mirian alertou Vera que, naquela tarde, carros de polícia passaram em frente ao prédio, observando o apartamento deles (Benjamin, 2013, p. 32). Essa informação fez com que os militantes, cientes dos riscos, suspendessem a reunião. Cid e Daniel saíram antes e avistaram os carros da polícia chegando. Vera e José Roberto também estavam saindo, quando resolveram voltar para auxiliar Carlos Zílio, que havia ficado responsável por sair com a metralhadora.

Zílio conseguiu escapar, mas no momento da saída de Vera e José Roberto o cerco se fechou e, após troca de tiros, que atingiu um dos policiais, ambos fugiram por caminhos diferentes. Vera escapou rendendo um táxi, fazendo-o rodar pela cidade, afastando qualquer possibilidade de descoberta pela polícia. José Roberto, segundo depoimento dos policiais que o perseguiram, fugiu a pé até a Avenida Brasil, onde pegou outro táxi, sem render o motorista (BNm 076, p. 71) Dali, foi ao aparelho de outro militante, José Ruivo, localizado na rua Taylor, na Lapa. Como resultado da perseguição até a Avenida Brasil, os policiais conseguiram anotar a placa do táxi e o encontraram, horas depois, quando transportava um novo passageiro, descobrindo, assim, o paradeiro de José Roberto (BNm 076, p. 172-173). Dando continuidade à perseguição, horas depois, na Rua Taylor, prenderam José Ruivo, enquanto que José Roberto conseguiu escapar ao pular pela janela do prédio e correr em direção à rua Joaquim Silva. Nesse trajeto, trocou tiros com um policial, aos gritos de "abaixo a ditadura” (BNm 076, p. 55). Refugiou-se em um dos quartos de um casarão na rua Joaquim Silva, avisando à moradora "que vinha de longe perseguido pela polícia”. Ela lhe deu um copo d'água e uma xícara de café e o avisou que os policiais estavam perto, fato que o fez se esconder embaixo da cama (BNm 076, p. 59). O resultado dessa perseguição foi a morte de José Roberto.

As informações que a ditadura divulgou à época sobre seu óbito são falsas. Segundo registro do DOPS, em um relato fantasioso, José Roberto foi localizado embaixo da cama e, em sua "sanha assassina", iniciou disparos contra os policiais que ali estavam para efetuar sua prisão. Na troca de tiros, teria sido atingido, vindo a falecer (BNm 076, p. 26-33). Todavia, no laudo do Instituto Médico Legal (IML) consta uma distância temporal significativa entre a suposta morte de José Roberto, às cinco e meia do dia dezessete, e a entrada do corpo no Instituto, às doze e trinta do mesmo dia (BNM 076, p. 667). Esse intervalo temporal chamou a atenção dos 
envolvidos na Comissão Especial sobre Mortos e Desaparecidos Políticos que, em 2007, analisou o caso de sua morte e, ao examinar detalhadamente o laudo do IML e relacioná-lo com as demais evidências do processo, constatou que:

José Roberto recebeu vários tiros, sendo que dois deles contestam a versão oficial. Examinando as fotos de perícia de local, verifica-se que o corpo fora encontrado em uma sala com o piso acarpetado, onde não havia espaço para que pudesse ter sido atingido, de longe, na coxa. O outro ferimento é sintomático de execução. [...] [Além disso] as escoriações se localizam em regiões do corpo humano que configuram tortura em pau-de-arara. Há ainda escoriações na região do punho, denotando que José Roberto foi algemado (BRASIL, 2007, p. 117).

José Roberto Spiegner, 21 anos de idade, ao contrário do relato produzido pelos agentes do DOPS, foi, portanto, preso, torturado e assassinado pelos órgãos de repressão. Foi o primeiro militante do MR-8 assassinado.

\section{“MEU COMPROMISSO TRANSCENDEU A QUALQUER COISA, ERA COM ELE, JOSÉ ROBERTO"}

Depois da fuga, Vera estava desnorteada. Pensava que José Roberto havia morrido na troca de tiros em frente ao apartamento. Além disso, conjecturava se um de seus tiros o haveria acertado. Apesar de tudo, dias depois, escreveu uma carta a Mirian. Naquele momento já sabia que ela havia delatado a presença deles no apartamento, como também já havia confirmado a morte de José Roberto. A carta é rica em significados, aponta os laços, mesmo que fugazes e puramente cotidianos, tecidos entre os militantes e os moradores. Para além disso, indica aspectos importantes da tentativa frustrada de vinculação com o povo - a construção utópica de "povo" - evidenciando que os revolucionários estavam dando suas vidas por eles e, principalmente, o isolamento social a que estavam submetidos.

Na carta demonstra, também, a dificuldade em construir laços políticos com os setores sociais que buscavam mobilizar para realizar a idealizada revolução brasileira. A súplica de Vera a Mirian, uma representante do "povo", para que ela apoiasse, como pudesse, a continuidade da luta armada era um sintoma do apoio que não vinha, e que não viria. Por fim, relata a dor da morte do companheiro José Roberto, que seria superada na luta, evidenciando o imperativo ofensivo que já citamos. Todos esses fatores justificam a longa citação: 
Mirian, um dia você me disse que se eu precisasse você me faria qualquer favor. Quero que você leia esta carta para nossos amigos e vizinhos e a esconda da repressão. Não quero que a repressão convença nossos amigos de que somos "terroristas" e cínicos. Que a nossa amizade era falsa. Isto não é verdade. Todo revolucionário é amigo do povo. É este o grande medo da ditadura dos patrões: que a gente tenha apoio do povo na guerra revolucionária. Pois aí está o segredo de nossa vitória. Somos a maioria do povo oprimido contra a minoria opressora. Lutamos por um mundo melhor onde não exista fome e miséria. Mas antes de conseguirmos isto, precisamos derrubar a ditadura dos patrões. [...] É isto tudo que quero que você explique ao pessoal do edifício, do bar, da padaria.

Outro favor: explique à Dita [filha de Mirian]. Me apeguei muito a ela. Gostaria que ela continuasse a me ver como sua amiga. Via os dois como os filhos que não pude ter em virtude da vida que escolhi.

Mirian, espero nesta longa guerra encontrar vocês do nosso lado. Hoje já peço o mínimo de ajuda: não deem informações à repressão. Não nos identifiquem, caso mostrem os retratos. Deem informações erradas. Se pedirem nossa descrição não deem. Vocês não podem ficar contra nós. Pois a nossa luta é a de vocês. Nossas vidas são dedicadas à causa do povo.

Quanto a mim, estou procurando reagir ao choque que levei. Na luta junto com meus companheiros encontrarei novas forças. Guerra é guerra. É sempre muito doloroso perder uma pessoa querida que, além disso, era um combatente valioso. É, acho que nossa rua está com urucubaca. Meu pesar se junta ao da Maria, D. Dulce e D. Filhinha.

Dê lembranças a todos, às crianças: um beijo grande. Ângela (BNm 076, p. 267268, grifos colocados).

Todavia, além do imperativo ofensivo, a partir da constatação da morte de José Roberto, a permanência de Vera Ślvia no MR-8 e na luta armada adquiriu outro significado. Conforme ela aponta em depoimento: "Meu compromisso transcendeu a qualquer coisa, era com ele, José Roberto” (MAGALHÃEs, 1986). Nesse sentido, a luta armada, para além da perspectiva de transformação social, adquiriu contornos de compromisso com o companheiro, devendo ser levada adiante a despeito de qualquer análise conjuntural que evidenciasse a marginalização social a que estavam submetidos e, no limite, a falência desse modo de luta política.

Nesse período, as investidas da repressão não davam tempo ao MR-8. Cerca de quinze dias após a morte de José Roberto, no dia 6 de março, Vera foi presa, em uma panfletagem na favela do Jacarezinho. Muito influenciada pela morte de 
José Roberto, gostaria de ter tido o mesmo destino que o companheiro. Mesmo cercada, sem possibilidade de fuga, deu início a um tiroteio. Uma das balas dos policiais atingiu, de raspão, sua cabeça. Fora de combate, foi presa junto a outros seis militantes. Na prisão, além das diversas torturas físicas, foi torturada psicologicamente com a morte de José Roberto, momento em que os torturadores reforçaram a ideia de que ela o havia assassinado. Em depoimento posterior, apontou as consequências dessas sessões de tortura: "Neste aspecto venceram. Apesar de protestar veementemente, introjetei de tal forma esta acusação que até hoje pago um preço alto por isso" (MaGalHães, s.d, p. 40).

Vera conviveu durante três anos com a possibilidade de ter assassinado José Roberto. Descobriu, apenas em 1973, que ele havia escapado do cerco na Penha, em diálogo com José Ruivo, em Santiago, antes do golpe contra Salvador Allende. Ela estava no exílio desde junho de 1970, quando foi libertada junto a outros 39 presos políticos em troca do embaixador da Alemanha Ocidental. Após passar por Argélia, Cuba e França, o Chile foi o local onde não apenas a luta armada, mas a perspectiva de militar politicamente deixou de fazer parte de seu horizonte. Ali, em conjunto com os amigos construídos no período de militância, tentava refletir sobre a derrota, não apenas de um projeto político, mas, como vimos, de um projeto de vida. Assim, realizava seu próprio inventário de cicatrizes, inapagáveis, como a morte de José Roberto, que levaria para o resto de sua vida.

\section{CONSIDERAÇ̃̃ES FINAIS}

Nosso objetivo foi, por meio da análise da trajetória de Vera Sílvia e José Roberto, discutir algumas perspectivas que fizeram parte do imaginário dos agrupamentos políticos que propuseram a luta armada como modo de derrubar a ditadura e realizar a revolução brasileira.

Em primeiro lugar, ressaltamos que a opção pela luta armada, ao menos relacionada à trajetória específica da DI-GB/MR-8, agregava um aspecto de revolução individual, existencial, numa tentativa de ruptura com as referências normativas da sociedade. Seletiva, propunha, principalmente, uma mudança no modo de conceber os relacionamentos afetivo-sexuais. Para Vera, especialmente, a militância incluía uma perspectiva de romper com o papel social imposto às mulheres.

Além disso, buscamos não apenas demonstrar os embates e aproximações entre amor e revolução naquele contexto, como também apresentar, através dessa relação, aspectos relevantes da vida na clandestinidade, realçando - apesar do total isolamento e marginalização social dos militantes e do seu projeto político, que não sensibilizou os setores sociais que buscavam mobilizar - o contato com os 
moradores das regiões suburbanas para as quais se deslocavam. Nesse sentido, a atitude ambivalente da vizinha Mirian denunciando e, ao mesmo tempo, avisando Vera sobre a possibilidade da chegada da polícia, e o refúgio dado por uma moradora a José Roberto enquanto este fugia, são sintomáticos de que as atitudes dos indivíduos não se enquadram na "cultura binária”, conforme as palavras de Pierre Laborie (2010), entre resistência e colaboração para com os regimes autoritários. Isso aponta para o amplo espaço entre os dois polos, em outras palavras, para a importância do olhar sobre a zona cinzenta.

Por fim, procuramos apresentar como a dinâmica clandestina afunilava e aprofundava as relações entre os militantes e, especialmente, como a morte dos companheiros afetou a militância política dos remanescentes. Com a marginalização social crescente das organizações, o compromisso com os companheiros presos e/ou mortos, número que aumentava gradativamente, transfigurava a permanência na luta armada em imperativo categórico, a despeito das evidências que apontavam para seu fracasso. Em síntese, buscamos demonstrar aspectos coletivos e individuais que estiveram presentes nas escolhas e nos dilemas vividos pelos militantes da esquerda armada brasileira, realçando, assim, a fertilidade das análises individuais para ampliação do conhecimento sobre o passado.

\section{REFERÊNCIAS BIBLIOGRÁFICAS}

Aarão Reis Filho, Daniel. A revolução faltou ao encontro. Os comunistas no Brasil. São Paulo: Brasiliense, 1990.

Acselrad, Henri. Sinais de fumaça na cidade: uma sociologia da clandestinidade na luta contra a ditadura no Brasil. Rio de Janeiro: Lamparina, 2015.

Baran, Paul; SweEzy, Paul. Capitalismo monopolista: ensaio sobre a ordem econômica e social americana. Rio de Janeiro: Zahar, 1966.

BeCKer, Jean-Jacques. "O handicap do a posteriori”. In: Amado, Janaína; FerreIra, Marieta. (Orgs.) Usos \& Abusos da História Oral. 8ª ed. Rio de Janeiro: Editora FGV, 2006, p. 27-32.

Benjamin, Cid. Gracias a la vida: Memórias de um militante. Rio de Janeiro: José Olympio, 2013.

Bnм (Brasil: Nunca Mais). Pasta-Processo: 076 e 603. Disponível em: http://bnmdigital. mpf.mp.br/pt-br/. Acesso em 24 de outubro de 2019.

Borges, Vavy Pacheco. "Desafios da Memória e da biografia: Gabrielle Brune-Sieler, uma vida (1874-1940)". In: Bresciani, Maria Stella; NAXARA, Marcia. (Orgs.) Memória e (Res)sentimento: indagações sobre uma questão sensível. $2^{\mathrm{a}}$ ed. Campinas: Editora da Unicamp, 2004, p. 287-312. 
BRASIL. Secretaria Especial dos Direitos Humanos. Comissão Especial sobre Mortos e Desaparecidos Políticos. Direito à verdade e à memória: Comissão Especial sobre Mortos e Desaparecidos Políticos. Brasília: Secretaria Especial dos Direitos Humanos, 2007.

Carvalho, Luiz Maklouf. Mulheres que foram à luta armada. São Paulo: Globo, 1998.

ChaIn, Arnaldo. Entrevista concedida a Daniel Aarão Reis e Vera Sílvia Magalhães. In: Arquivo Público do Estado do Rio de Janeiro. Fundo Vera Sílvia Magalhães, 1988. Debray, Regis. Revolução na Revolução?. São Paulo: Centro Ed. Latino Americano, s.d. Dosse, François. O desafio biográfico: escrever uma vida. $2^{\text {a }}$ ed. São Paulo: Edusp, 2015. Elias, Norbert. A sociedade dos indivíduos. Rio de Janeiro: Zahar, 1994.

Fico, Carlos. Como eles agiam. Os subterrâneos da Ditadura Militar: espionagem e polícia política. Rio de Janeiro: Editora Record, 2001.

Frank, André Gunder. "A agricultura brasileira: capitalismo e mito do feudalismo". In: StEdile, João Pedro (Org.) A questão agrária no Brasil: o debate na esquerda (19601980). Vol. 2. São Paulo: Expressão Popular, 2012, p. 35 - 100.

Furtado, Celso. Dialética do desenvolvimento. Rio de Janeiro: Editora Fundo de Cultura, 1964.

Gabeira, Fernando. O que é isso, companheiro?. Rio de Janeiro: Codecri, 1979.

GuEvara, Ernesto “Che”. Obra revolucionaria. Organização Roberto Fernandez Retamar. $2^{\mathrm{a}}$ ed. México, DF: Era, 1968.

Guerra de Guerrilhas (1960), 10ª ed. São Paulo: edições populares, 1987

LABORIe, Pierre. "1940-1944. Os franceses do pensar-duplo”. In: Quadrat, Samantha; Rollemberg, Denise. (Orgs.). A construção social dos regimes autoritários: Europa, volume I. Rio de Janeiro: Civilização Brasileira, 2010, p. 31-44.

LÊNIn, Vladimir. Obras escolhidas, tomo I. $3^{\text {a }}$ ed. São Paulo: Alfa-Ômega, 1986

Levi, Giovanni. "Usos da biografia”. In: Amado, Janaína; Ferreira, Marieta. (Orgs.) Usos \& Abusos da História Oral. 8ª ed. Rio de Janeiro: Editora FGV, 2006, p. 167-182. LoRIGA, Sabina. "A biografia como problema”. In: Revel, Jacques. (Org.) Jogos de escala: A experiência da microanálise. Rio de Janeiro: Editora FGV, 1998, p. 225-250.

Magalhães, Vera Sílvia. Entrevista concedida a Marcelo Ridenti. In: Arquivo Edgar Leuenroth. Militância Política e Luta Armada, 1986.

Provisórias Memórias. In: Arquivo Público do Estado do Rio de Janeiro. Fundo Vera Sílvia Magalhães, s.d.

Martinho, Francisco Carlos Palomanes. A monografia de um tempo português. Tempo, v. 17, n. 31, p. 313-316, 2011.

Martins Filho, João Martins Movimento estudantil e ditadura militar: 1964-1968 Campinas, SP: Papirus, 1987. 
MARx, Karl. Manuscritos Econômico-filosóficos. São Paulo: Boitempo, 2004.

МоттA, Rodrigo Patto Sá. As universidades e o regime militar: cultura política brasileira e modernização autoritária. Rio de Janeiro: Zahar, 2014.

Polari de Alverga, Alex. Inventário de cicatrizes. $2^{\mathrm{a}}$ ed. Rio de Janeiro: Comitê Brasileiro pela Anistia, 1978.

Pollak, Michael. Memória, Esquecimento, Silêncio. Revista Estudos Históricos, v. 2, n. 3, p. 3-15, 1989.

Prado Júnior, Caio. A revolução brasileira. São Paulo: Brasiliense, 1987.

Priore, Mary Del. Biografia: quando o indivíduo encontra a história. Topoi, v. 10, n. 19, p. 7-16, jul-dez 2009.

Reich, Wihelm. A revolução sexual. $8^{\mathrm{a}}$ ed. Rio de Janeiro: Zahar, 1981.

Ricoevr, Paul. Tempo e narrativa, tomo I. Campinas: Papirus, 1994.

Ridenti, Marcelo. O fantasma da revolução brasileira. $2^{\text {a }}$ ed. São Paulo: Editora da UNESP, 2010.

. The Debate over Military (or Civilian-Military?) Dictatorship in Brazil in Historiographical Context. Bulletin of Latin American Research, v. 37, n. 1, p. 33-42, 2016. Disponível em: http://onlinelibrary.wiley.com/doi/10.1111/blar.12519/full. Acesso em 24 de outubro de 2019.

SArlo, Beatriz. Tempo Passado: Cultura da memória e guinada subjetiva. São Paulo: Companhia das Letras; Belo Horizonte: UFMG, 2007. 